$\begin{array}{ll}\text { Research Square } & \begin{array}{l}\text { Preprints are preliminary reports that have not undergone peer review. } \\ \text { They should not be considered conclusive, used to inform clinical practice, } \\ \text { or referenced by the media as validated information. }\end{array}\end{array}$

\title{
Implementation of the Findings From the American College of Surgeons Oncology Group Z0011 Study in Axillary Management in Patients With Invasive Breast Cancer: A Cohort Study in a Brazilian Public University Hospital
}

Vanessa Monteiro Sanvido ( $\square$ vanessasanvido@gmail.com )

Unifesp EPM: Universidade Federal de Sao Paulo Escola Paulista de Medicina https://orcid.org/0000-0003-3116-3550

\section{Simone Elias}

Unifesp EPM: Universidade Federal de Sao Paulo Escola Paulista de Medicina

\section{Gil Facina}

Unifesp EPM: Universidade Federal de Sao Paulo Escola Paulista de Medicina

Silvio Eduardo Bromberg

Hospital Israelita Albert Einstein

\section{Afonso Celso Pinto Nazário}

Unifesp EPM: Universidade Federal de Sao Paulo Escola Paulista de Medicina

\section{Research article}

Keywords: early breast cancer, metastases, positive sentinel lymph node, axillary lymph node dissection, axillary therapy

Posted Date: June 16th, 2021

DOI: https://doi.org/10.21203/rs.3.rs-605800/v1

License: (1) This work is licensed under a Creative Commons Attribution 4.0 International License. Read Full License 


\section{Abstract}

Background: To evaluate and compare overall survival and locoregional recurrence between patients with invasive breast tumors and sentinel node metastasis undergoing sentinel lymph node dissection (SLND) alone and those undergoing \\ complete axillary lymph node dissection (ALND).

Methods: In this retrospective cohort study, we reviewed medical records of all consecutive patients with primary invasive breast carcinoma who had undergone conservative surgery at a public university hospital in Brazil between 2008 and 2018. We evaluated the overall survival and the onset of locoregional recurrence using Kaplan-Meier and Cox regression analyses, respectively.

Results: Overall, 97 participants underwent conservative breast surgery, 41 in the ALND group, and 56 in the SLND group. The mean age was 57.8 years. Only $17 \%$ of the patients in the ALND group had an additional biopsy-proven axillary disease, and $83 \%$ were treated with complete dissection unnecessarily. The 5-year survival rates were 80.1 and $87.5 \%$ in the SLND and ALND groups, respectively $(p=0.376)$. Locoregional recurrence was rare $(1.8 \%$ and $7.7 \%$ in the SLND and ALND groups, respectively; $p=0.196)$. Intraoperative assessment was performed in $90.2 \%$ and $30.8 \%$ cases $(p<0.00001)$ before and after ACOSOG Z0011, respectively. Additionally, a second surgical procedure was performed in 3.8\% of cases after ACOSOG Z0011 criteria adoption.

Conclusions: Overall survival and locoregional recurrence were similar between the two groups. The de-escalation of ALND to SLND in women with metastasis in the sentinel lymph node treated with conservative surgery and radiotherapy is feasible even in developing countries.

\section{Introduction}

Breast cancer is the most common type of cancer worldwide and is responsible for $15 \%$ of cancer-related deaths among women. ${ }^{1}$ Sociodemographic index levels are significant determinants of breast cancer incidence and mortality. In low-income and middleincome countries, the incidence rate of breast cancer is low. ${ }^{2}$ However, breast cancer mortality remains high due to limitations in early diagnosis and treatment options. ${ }^{3,4}$

In recent decades, the standard axillary management of early-stage breast cancer has changed dramatically. Axillary lymph node dissection (ALND) has been replaced by sentinel lymph node dissection (SLND) for treating patients with node-negative breast cancer. ${ }^{5}$ The American College of Surgeons Oncology Group (ACOSOG) Z0011 was a milestone in the surgical treatment of the axilla in patients with early breast cancer that contributed significantly to reducing the extent of breast surgery. ${ }^{6-11}$ Consequently, treatment of the axilla resulted in reduced morbidity and improved quality of life. ${ }^{12-14}$

ACOSOG Z0011 was a randomized, and non-inferiority clinical trial, including women with invasive breast tumors sized up to $5 \mathrm{~cm}$, with clinically negative axilla and up to two metastatic sentinel lymph nodes. Patients were treated with conservative surgery, breast radiotherapy, and systemic adjuvant therapy. That study concluded that complete ALND neither significantly improved overall survival or disease-free survival nor did it reduce locoregional recurrence in these patients. ${ }^{15,16}$ The ACOSOG Z0011 data were updated with a 10-year follow-up, and the results confirmed the evidence, which resulted in fundamental changes in the surgical management of the axilla. ${ }^{17,18}$

Other studies have corroborated the results of the Z0011trial. NSABP B4 found no benefit with resection of positive occult lymph nodes at the time of surgery. ${ }^{19}$ IBCSG $23-01$ also evaluated patients with minimal lymph node involvement and showed that ALND could be avoided. ${ }^{20}$ The AMAROS trial confirmed that axilla treatment (surgery or radiotherapy) in patients with metastatic axillary sentinel lymph nodes provides comparable axillary control and there were no significant differences in overall survival between treatment groups. Additionally, axillary radiotherapy can be used as an alternative to ALND in patients with metastasis in the sentinel lymph node and fulfilling the ACOSOG Z0011 exclusion criteria. ${ }^{21}$

However, several shortcomings were identified in the Z0011 trial, such as enrollment not meeting the accrual goal, absence of standard testing for human epidermal growth factor receptor 2 (HER2), doubts about the radiotherapy fields, and applicability to other patient populations. ${ }^{22}$ 
In Brazil, the utility of the conservative approach to the axilla in patients with positive sentinel lymph node biopsies has been challenged because survival after breast cancer remains poor in developing countries ${ }^{23}$ due to delays in diagnosis, which occurs in more advanced stages when treating the disease is difficult. ${ }^{24}$ In addition, there is resistance in some cancer centers to adhere to the new surgical approach. These facts motivated this study.

This study aimed to validate the applicability of the Z0011 trial approach by evaluating and comparing the overall survival and locoregional recurrence in patients with invasive breast cancer who underwent either SLND as indicated by biopsy or complete ALND.

\section{Materials And Methods \\ Study design, setting, and ethics}

This was a retrospective cohort study based on medical records evaluating the survival in consecutive patients with primary invasive carcinoma of the breast who underwent conservative surgery at a public university hospital in Brazil (Hospital São Paulo, Universidade Federal de São Paulo, UNIFESP) between February 2008 and December 2018. We evaluated overall survival and locoregional recurrence in patients who underwent either SLND or ALND.

This project was approved by the institutional review board. Patients were informed about the study objectives, and they agreed to have their clinical data used in the research without any incentive and signed an informed consent form.

\section{Participants, sources of data, and treatments received}

We reviewed an electronic database of the surgical ward records to identify patients (only women) who underwent surgery during the study period for a primary breast tumor of size up to $5 \mathrm{~cm}$. We excluded patients who underwent a mastectomy, complete axillary lymph node resection without a previous sentinel lymph node biopsy, or those who received neoadjuvant therapy. We considered only women who underwent conservative breast surgery and sentinel lymph node biopsy. Next, we excluded patients who had negative sentinel lymph node biopsy test findings. Therefore, only those who underwent conservative surgery (quadrantectomy) and had positive sentinel lymph nodes were finally included. The axillae of these women were clinically negative (N0).

We divided the participants into two groups: the ALND group included patients who underwent complete ALND and SLND group included those who underwent dissection of only the axillary nodes indicated by the sentinel lymph node biopsy. Figure 1 shows the treatment protocols for patients at our hospital before and after the publication of the Z0011 trial. The only Z0011 trial criterion that was not considered at our hospital was the presence of extracapsular extension identified as focal or smaller than $2 \mathrm{~mm}$. These patients were treated with SLND.

During the study period, ultrasonography was not routinely performed at our hospital. Sentinel lymph node biopsy was performed using patent blue dye, and some patients were treated using a combined technique with technetium-99m. Lymphoscintigraphy was not routinely performed because of the lack of resources at our hospital. Intraoperative assessment of sentinel lymph nodes could be performed during surgery at the surgeon's discretion.

\section{Study endpoint, variables, and sample size calculation}

We compared survival between the groups. The primary endpoint was overall survival, which was defined as the time between surgery and death for any cause. Secondary endpoints were locoregional recurrence, which was determined by the return of the disease either in the breast, ipsilateral lymph nodes in the axilla, or in the internal supraclavicular, infraclavicular, or thoracic (mammary) chains and survival after the recurrence of the disease, which was considered as the time between surgery and the onset of locoregional recurrence.

We also compared sociodemographic and clinical variables such as age group (younger than 50 years or aged 51 years or older), race, educational level, histological diagnosis and grade, angiolymphatic invasion, hormonal receptors, HER-2 positivity, Ki-67, tumor size, number of positive lymph nodes, and therapy between the groups.

The sample size was calculated to detect the non-inferiority of risks (hazard ratio) with a power of $85 \%$ and a significance level of $5 \%$. We admitted a non-inferiority margin of 0.30 for the risks and a follow-up of 5 years, in which we assumed an approximately 
exponential distribution. A minimum sample size of 43 patients for each group (total, 86 patients) was determined. We used PASS 14 software (Power Analysis and Sample Size System, NCSS) for this calculation.

\section{Statistical analysis}

We analyzed the data descriptively. For categorical variables, we present absolute and relative frequencies and, for numerical variables, summary measures (mean, quartiles, minimum, maximum, and standard deviation).

We verified associations between two categorical variables using a Chi-square test or in cases of small samples with a Fisher's exact test. We compared two means using a student's t-test for independent samples, with the assumption of normality verified using a Kolmogorov-Smirnov test.

The survival analyses in this study evaluated the time until the occurrence of death or recurrence, considering censorship (cases that did not experience the event during the analysis period). Initially, we analyzed survival functions separately for each predictor variable (univariate analysis). Kaplan-Meier models were used for categorical variables. We estimated survival functions for each level of these variables, and then compared them using a log-rank test (Mantel-Cox).

Additionally, we adjusted univariate Cox regression models for all the predictor variables considered, and a multivariate Cox model was adjusted for significant characteristics identified in the univariate models (backward method). A Cox's model assumes the existence of proportional risks, which was verified via a test based on Schoenfeld residuals.

All statistical tests were two-tailed, and a significance level of $5 \%$ was used. Statistical analyses were performed using the statistical software Statistical Package for the Social Sciences (SPSS) 20.0 and STATA 12.

\section{Results}

\section{Patient characteristics}

During the study period, 1009 patients underwent surgery for breast cancer in our hospital. After applying the exclusion criteria, we identified 97 patients with positive lymph nodes who underwent conservative breast surgery. These patients were diagnosed with invasive breast carcinoma, with tumors of $2 \mathrm{~cm}$ or less (T1) or $2.1 \mathrm{~cm}$ to $5 \mathrm{~cm}$ (T2), all with clinically negative axilla (N0). There were 41 and 56 patients in the ALND and SLND groups, respectively (Figure 2).

The mean age was similar between the groups (Table 1). The mean tumor size was $1.7 \mathrm{~cm}$, and significantly larger in the ALND group $(p=0.048)$. The number of positive lymph nodes was significantly higher in the ALND group $(m e d i a n, 2)$ than in the SLND group (median: 1). Only one lymph node was positive in $91 \%$ of the cases. In the ALND group, only $17 \%$ of patients had an additional axillary disease (as shown by biopsy), suggesting that complete dissection performed in $83 \%$ of patients was unnecessary. The ALND group had a significantly higher number of total lymph nodes removed (median, 14$)$ than the SLND group did (2 nodes). The ALND group also had a significantly longer follow-up time than the SLND group did (median, 5.3 vs. 3.5 years).

There was no difference in race, educational level, histological diagnosis and grade, hormonal receptors, HER-2 positivity, tumor size (according to TNM pathological staging), and angiolymphatic invasion between the groups (Table 2). However, the ALND group had a significantly higher number of positive lymph nodes and macrometastases ( $p<0.001$ for both), as well as higher axillary involvement, as seen by the higher frequency of pN1, pN2, and pN3 cases, than the other group did $(p<0.001)$. The SLND group had less extracapsular extension $(p<0.001)$. Adjuvant chemotherapy was more frequent in the ALND group $(p=0.024)$. Furthermore, the types of radiotherapy and hormonal therapy performed were similar between the groups.

Radiation oncologists at our institution used nomograms to predict the likelihood of metastasis in non-sentinel lymph nodes and helped in clinical decision-making. The most commonly used nomograms were from the Memorial Sloan-Kettering Cancer Center ${ }^{25}$ and MD Anderson Cancer Center. ${ }^{26}$ Patients who had greater than $30 \%$ risk of additional lymph node involvement were treated with drainage radiotherapy, ${ }^{27}$ although it is not recommended in the ACOSOG Z0011 protocol. We identified $12.5 \%$ and $4.9 \%(p=0.12)$ cases that received drainage radiotherapy in the SLND alone and ALND groups, respectively.

There was a significant reduction in the intraoperative assessment of sentinel lymph nodes after the publication of the ACOSOG Z0011 clinical trial and its adoption as a guideline at our hospital. Of the 415 patients evaluated, $90.2 \%$ (46 of 51 patients operated) 
were subjected to the exam before and $30.8 \%$ (112 of 364) after the publication. The rate of patients undergoing a second surgery as a result of the anatomopathological result was $3.8 \%$, and the main indications for the second surgical procedure were the presence of three or more positive lymph nodes and gross capsular extravasation.

\section{Overall survival}

The mean overall survival was 9.18 years (95\% confidence interval $[\mathrm{Cl}], 8.47-9.90)$. There was no difference in survival between the two groups; the 5-year overall survival was $80.1 \%$ and $87.5 \%$ in the SLND and ALND groups $(p=0.376$ ), respectively (Figure 3 ). Only hormonal therapy had a significant effect on survival; patients who had positive hormone receptors lived longer (Table 3). Patients with negative receptors for estrogen (ER) and progesterone (PR) had shorter survival, but only two patients were classified as such; therefore, they were not considered (Table 1). All patients positive for HER2 received targeted therapy, and there was no difference in survival between patients with positive and negative HER2 status.

In the survival model, only hormonal therapy had a significant effect $(p=0.018$, Table 4$)$, and patients receiving this therapy had a $78 \%$ lower risk of death. As in the previous analysis, the two patients who were ER- and PR+ were not considered.

The multivariate Cox regression model included groups, hormonal therapy, tumor size ( $\mathrm{pT}$ ), the number of resected lymph nodes, capsular extension, the size of axillary metastasis, and adjuvant chemotherapy (Table 5). We did not consider the number of affected lymph nodes because some staging categories were present in only one group. In this analysis, there was no difference in survival between the groups $(p=0.536)$ (Table 5). However, the risk of death was $91 \%$ lower in patients undergoing hormonal therapy in the final model $(p=0.005)$ and $86 \%$ lower in those treated with adjuvant chemotherapy $(p=0.027)$. The Schoenfeld residuals testing showed that the hazards were proportional in the initial model $(p=0.453)$ and at the end $(p=0.194)$, indicating the absence of violation of this assumption.

\section{Locoregional recurrence}

Locoregional recurrence was a rare event, with only four patients having disease recurrence: $7.7 \%$ of patients in the ALND group and $1.8 \%$ in the SLND group. Recurrence occurred in all cases within 18 months of follow-up. There was no significant difference in survival after disease recurrence $(p=0.196)$ between the groups (Table 6). Survival after recurrence was 10.1 years $(95 \% \mathrm{Cl} 9.62$ 10.40). Figure 4 shows the accumulated survival per group.

\section{Discussion}

This study showed that survival was not improved in patients with invasive carcinoma when we performed complete ALND. The similar overall survival between the two groups provides evidence that ALND is unnecessary in patients with metastatic sentinel lymph nodes treated with conservative surgery and radiotherapy. This finding suggests that even in countries such as Brazil, where the overall survival in patients with breast cancer is lower than that in patients in developed nations, ${ }^{23}$ conservative surgical treatment of the axilla is possible. This result corroborates the data from the ACOSOG Z0011 trial. ${ }^{15}$

Patients who underwent SLND alone had a lower survival rate, although this was not statistically significant. This is probably because, in our study, patients in the SLND group received adjuvant chemotherapy less frequently $75 \%$ vs. $92.7 \%$ in SLND alone and ALND, respectively, $p=0.024$, Table 1 ). Additionally, they were administered adjuvant chemotherapy because of comorbidities, and these data were not evaluated in the study.

The tendency towards reducing the use of intraoperative lymph node evaluation after the publication of the ACOSOG Z0011 trial was similar to that in other studies. $6,7,28,29$ Intraoperative assessment of the sentinel lymph node can be associated with a shorter average time of surgery, ${ }^{6}$ a reduction in perioperative costs, ${ }^{30,31}$ and a significant increase in the proportion of patients in whom complete dissection can be avoided. ${ }^{32}$ According to van der Noordaa et al., ${ }^{33}$ intraoperative assessments of the sentinel lymph node should be performed only in patients with a restricted indication of lymph node dissection in the presence of metastasis in sentinel lymph node biopsy. Thus, the intraoperative assessment of the sentinel lymph node is not necessary for patients who meet the ACOSOG Z0011 criteria, and the surgical re-approach resulting from the definitive anatomopathological result of the axilla is rare (3.8\%). This is an important finding in our study that can promote the practice of avoiding the intraoperative assessment of sentinel lymph nodes. 
Locoregional recurrence was rare and similar between the groups. We believe that we had adequate follow-up time to evaluate recurrence. Long-term follow-up data from the NSABP trial ${ }^{19}$ showed that recurrence usually occurred early, at 14.8 months on average. In the ACOSOG Z0011 trial, ${ }^{18}$ recurrences occurred in 3.1 years, a bit shorter than our average follow-up time of 3.7 years.

The SLND group included women who were postmenopausal, with small tumors (pT1), positive hormone receptors, and small axillary involvement (35.7\% with micrometastasis in the sentinel lymph node biopsy). These characteristics were similar to those of the same arm in the Z0011 trial. ${ }^{15,18}$ However, in the Z0011 study, ${ }^{15}$ the arm undergoing complete axillary dissection also had a high prevalence of micrometastases (37.5\%), different from our study.

For patients with HER2 overexpression, triple-negative tumors and those aged below 50 years, using the ACOSOG Z0011 trial criteria can be discussed. Chung et al. ${ }^{34}$ reported no benefit of performing ALND in this subgroup. In our study, the groups were homogeneous in terms of these three variables. The underrepresentation of this group in the ACOSOG Z0011 trial may be due to the local demographic characteristics of patients with breast carcinoma. Nevertheless, it was assumed that the distribution of HER2 positive tumors was balanced between the two arms of the trial.

Several studies around the world have identified increasing acceptance of the Z0011 results and a change in clinical practice in relation to the standard treatment of axillary lymph nodes in patients with breast cancer. ${ }^{35-38}$.

A meta-analysis comparing SLND/radiotherapy only with ALND in early-stage breast cancer with limited sentinel node metastasis estimated that overall survival and disease-free survival were higher in the SLND group than in the ALND group and observed a greater axillary recurrence in the SLND/radiotherapy group. In conclusion, the omission of ALND in patients with one or two sentinel lymph nodes (SLNs) is indicated. ${ }^{39}$

Another meta-analysis of real-world cases evaluating the effects of SLND alone in patients with early-stage breast cancer and one or two positive SLN metastases in the post-Z011 era showed equivalent survival and recurrence outcomes between those undergoing SNLD alone or ALND, demonstrating that SLND alone was safe. ${ }^{40}$ However, this shift in clinical practice should not occur in patients with residual lymph node disease following neoadjuvant chemotherapy ${ }^{41}$ All these studies included patients who were treated with systemic adjuvant therapy.

Complete ALND might be an overtreatment for many patients with capsular extravasation in the dissected sentinel lymph nodes. The Z0011 trial excluded patients with gross capsular extravasation and did not analyze the effect of microscopic capsular extravasation on recurrence or survival, making the management of these patients uncertain. ${ }^{15,18}$ The extension of capsular extravasation is directly associated with the burden of axillary disease. ${ }^{42}$ However, the rates of local, regional, or distant recurrence or mortality were similar between patients with and without capsular extravasation of $\leq 2 \mathrm{~mm},{ }^{43}$ and regional recurrence was rare and equal to that in patients without capsular extravasation even in the absence of nodal radiotherapy. Capsular extravasation is not the only reason for complete ALND. ${ }^{44}$ In our study, we identified five patients with capsular extravasation of $\leq 2 \mathrm{~mm}$ who were treated with SLND alone, avoiding the morbidity associated with complete axillary resection. However, these patients received regional radiotherapy at our hospital.

We acknowledge that translating the Z0011 results into clinical practice is complicated by the inconsistent use of radiotherapy fields in their study. In a prospective study of 793 patients with sentinel lymph node metastasis, using the ACOSOG Z0011 eligibility criteria resulted in the avoidance of ALND in $84 \%$ of patients, and the 5 -year cumulative regional recurrence rate was $1 \%$, which did not differ between radiotherapy fields. The authors concluded that even without the routine use of nodal radiotherapy, complete dissection could be avoided with excellent regional control. ${ }^{45}$ Hopefully, we will have answers about the real influence of radiotherapy in regional control with the results of the ongoing trials. ${ }^{46-49}$.

This was a retrospective study based on the medical records, which did not allow us to evaluate costs and surgical times after the change in the clinical approach in our hospital after the publication of the ACOSOG Z0011 study. Studies that evaluated cost reduction associated with the elimination of complete axillary dissection, ${ }^{30,31}$ did not consider the risk of surgical re-approach due to the presence of more than two sentinel lymph nodes compromised with macrometastasis or capsular extravasation. The cost of a second surgery remains to be evaluated. Even the ACOSOG Z0011 trial did not report the rate of surgical re-approach in the group subjected to SLND alone. The rate of surgical re-approach in this study was too low to answer this question. Nevertheless, this was 
the first study in our country to address the implementation of the findings of Z0011 and was important to encourage conservative surgical treatment of the axilla in our country and other developing countries, with the aim of disseminating this practice and benefiting patients.

The preliminary internal evaluation of the results of this study prompted major changes in our hospital's clinical approach, with more conservative surgeries being performed and the elimination of ultrasonography, findings of which would often cause patients to undergo radical lymphadenectomy in the absence of sentinel lymph node biopsy results in the past.

\section{Conclusions}

The overall survival and locoregional recurrence in patients with metastatic axillary sentinel lymph nodes treated with SLND were similar to those in patients treated with complete ALND. The elimination of routine axillary lymphonodectomy and the implementation of sentinel node biopsy at our hospital benefited the patients who could be treated with less aggressive surgery. The de-escalation of ALND to SLND in women with metastasis in the sentinel lymph node treated with conservative surgery and radiotherapy is possible. Our study showed that it is possible to apply the ACOSOG Z0011 recommendation in developing countries.

\section{Abbreviations}

ACOSOG: American College of Surgeons Oncology Group

ALND: axillary lymph node dissection

Cl: confidence interval

ER: estrogen receptor

HER2: human epidermal growth factor receptor 2

HR: hazard ratio

IBCSG: International Breast Cancer Study Group

NSABP: National Surgical Adjuvant Breast and Bowel Project

PASS: Power Analysis and Sample Size System

PR: progesterone receptor

SLN: sentinel lymph node

SLND: sentinel lymph node dissection

SPSS: Statistical Package for the Social Sciences

\section{Declarations}

\section{- Ethics approval and consent to participate}

The Institutional Review Board of Universidade Federal de São Paulo, number 1214/2016, approved this project. All the procedures of the study were in accordance with the ethical standards of the Helsinki declaration. Patients were informed about the study objectives and agreed to have their clinical data used in the research without any incentive, signing an informed consent form.

\section{- Consent for publication}

Not applicable

\section{- Availability of data and materials}


The datasets used and/or analyzed during the current study are available from the corresponding author on reasonable request.

\section{- Competing interests}

The authors declare that they have no competing interests.

\section{- Funding}

The first author (VMS) was supported by a doctoral scholarship from Conselho Nacional de Desenvolvimento Científico e Tecnológico. No other funding was received for this study.

\section{- Authors' contributions}

VMS designed the study, performed the experiments, analyzed the data, and wrote the manuscript; SE revised the manuscript; GF revised the manuscript; ACPN designed the study, analyzed the data and revised the manuscript. All authors read and approved the final manuscript.

\section{- Acknowledgements}

We are extremely grateful to Prof. Dr. Armando Giuliano for his review of and suggestions regarding this manuscript. We are very honored.

\section{- Authors' information}

1. Department of Gynecology, discipline of Mastology, Universidade Federal de São Paulo (UNIFESP), São Paulo, SP,

Brazil. Vanessa Monteiro Sanvido, Simone Elias, Gil Facina, Silvio Eduardo Bromberg, Afonso Celso Pinto Nazário

2. Hospital do Coração (HCor), São Paulo, SP, Brazil Vanessa Monteiro Sanvido \& Afonso Celso Pinto Nazário

3. Hospital Israelita Albert Einstein (HIAE), São Paulo, SP, Brazil. Vanessa Monteiro Sanvido \& Silvio Eduardo Bromberg

\section{References}

1. Bray F, Ferlay J, Soerjomataram I, Siegel RL, Torre LA, Jemal A. Global cancer statistics 2018: GLOBOCAN estimates of incidence and mortality worldwide for 36 cancers in 185 countries [published correction appears in CA Cancer J Clin. 2020 Jul;70(4):313]. CA Cancer J Clin. 2018;68(6):394-424. doi:10.3322/caac.21492.

2. Hu K, Ding P, Wu Y, Tian W, Pan T, Zhang S. Global patterns and trends in the breast cancer incidence and mortality according to sociodemographic indices: an observational study based on the global burden of diseases. BMJ Open. 2019;9(10):e028461. doi:10.1136/bmjopen-2018-028461. Published 2019 Oct 7.

3. Heer E, Harper A, Escandor N, Sung H, McCormack V, Fidler-Benaoudia MM. Global burden and trends in premenopausal and postmenopausal breast cancer: a population-based study. Lancet Glob Health. 2020;8(8):e1027-37. doi:10.1016/S2214109X(20)30215-1.

4. Dreyer MS, Nattinger AB, McGinley EL, Pezzin LE. Socioeconomic status and breast cancer treatment. Breast Cancer Res Treat. 2018;167(1):1-8. doi:10.1007/s10549-017-4490-3.

5. Giuliano AE, Haigh PI, Brennan MB, et al. Prospective observational study of sentinel lymphadenectomy without further axillary dissection in patients with sentinel node-negative breast cancer [published correction appears in J Clin Oncol $2000 \mathrm{Nov}$ 15;18(22):3877]. J Clin Oncol. 2000;18(13):2553-9. doi:10.1200/JC0.2000.18.13.2553.

6. Caudle AS, Hunt KK, Tucker SL, et al. American College of Surgeons Oncology Group (ACOSOG) Z0011: impact on surgeon practice patterns. Ann Surg Oncol. 2012;19(10):3144-51. doi:10.1245/s10434-012-2531-Z.

7. Weiss A, Mittendorf EA, DeSnyder SM, et al. Expanding Implementation of ACOSOG Z0011 in Surgeon Practice. Clin Breast Cancer. 2018;18(4):276-81. doi:10.1016/j.clbc.2017.10.007.

8. Robinson KA, Pockaj BA, Wasif N, Kaufman K, Gray RJ. Have the American College of Surgeons Oncology Group Z0011 trial results influenced the number of lymph nodes removed during sentinel lymph node dissection? Am J Surg. 2014;208(6):1060-4. doi:10.1016/j.amjsurg.2014.08.009. 
9. Yao K, Yao K, Liederbach E, Pesce C, Wang CH, Winchester DJ. Impact of the American College of Surgeons Oncology Group Z0011 Randomized Trial on the Number of Axillary Nodes Removed for Patients with Early-Stage Breast Cancer. J Am Coll Surg. 2015;221(1):71-81. doi:10.1016/j.jamcollsurg.2015.02.035.

10. Mann JM, Wu X, Christos P, Nagar H. The State of Surgical Axillary Management and Adjuvant Radiotherapy for Early-stage Invasive Breast Cancer in the Modern Era. Clin Breast Cancer. 2018;18(4):e477-93. doi:10.1016/j.clbc.2017.09.001.

11. Tsao MW, Cornacchi SD, Hodgson N, et al. A Population-Based Study of the Effects of a Regional Guideline for Completion Axillary Lymph Node Dissection on Axillary Surgery in Patients with Breast Cancer. Ann Surg Oncol. 2016;23(10):3354-64 doi:10.1245/s10434-016-5310-4.

12. Lucci A, McCall LM, Beitsch PD, et al. Surgical complications associated with sentinel lymph node dissection (SLND) plus axillary lymph node dissection compared with SLND alone in the American College of Surgeons Oncology Group Trial Z0011. J Clin Oncol. 2007;25(24):3657-63. doi:10.1200/JC0.2006.07.4062.

13. Mansel RE, Fallowfield L, Kissin M, et al. Randomized multicenter trial of sentinel node biopsy versus standard axillary treatment in operable breast cancer: the ALMANAC Trial [published correction appears in J Natl Cancer Inst. 2006 Jun 21;98(12):876]. J Natl Cancer Inst. 2006;98(9):599-609. doi:10.1093/jnci/djj158.

14. Ashikaga T, Krag DN, Land SR, et al. Morbidity results from the NSABP B-32 trial comparing sentinel lymph node dissection versus axillary dissection. J Surg Oncol. 2010;102(2):111-8. doi:10.1002/jso.21535.

15. Giuliano AE, Hunt KK, Ballman KV, et al. Axillary dissection vs no axillary dissection in women with invasive breast cancer and sentinel node metastasis: a randomized clinical trial. JAMA. 2011;305(6):569-75. doi:10.1001/jama.2011.90.

16. Giuliano AE, McCall L, Beitsch P, et al. Locoregional recurrence after sentinel lymph node dissection with or without axillary dissection in patients with sentinel lymph node metastases: the American College of Surgeons Oncology Group Z0011 randomized trial. Ann Surg. 2010;252(3):426-33. doi:10.1097/SLA.0b013e3181f08f32.

17. Giuliano AE, Ballman KV, McCall L, et al. Effect of Axillary Dissection vs No Axillary Dissection on 10-Year Overall Survival Among Women With Invasive Breast Cancer and Sentinel Node Metastasis: The ACOSOG Z0011 (Alliance) Randomized Clinical Trial. JAMA. 2017;318(10):918-26. doi:10.1001/jama.2017.11470.

18. Giuliano AE, Ballman K, McCall L, et al. Locoregional Recurrence After Sentinel Lymph Node Dissection With or Without Axillary Dissection in Patients With Sentinel Lymph Node Metastases: Long-term Follow-up From the American College of Surgeons Oncology Group (Alliance) ACOSOG Z0011 Randomized Trial. Ann Surg. 2016;264(3):413-20. doi:10.1097/SLA.0000000000001863.

19. Fisher B, Jeong JH, Anderson S, Bryant J, Fisher ER, Wolmark N. Twenty-five-year follow-up of a randomized trial comparing radical mastectomy, total mastectomy, and total mastectomy followed by irradiation. N Engl J Med. 2002;347(8):567-75. doi:10.1056/NEJMoa020128.

20. Galimberti V, Cole BF, Zurrida S, et al. Axillary dissection versus no axillary dissection in patients with sentinel-node micrometastases (IBCSG 23 - 01): a phase 3 randomised controlled trial [published correction appears in Lancet Oncol. 2013 Jun;14(7):e254]. Lancet Oncol. 2013;14(4):297-305. doi:10.1016/S1470-2045(13)70035-4.

21. Donker M, van Tienhoven G, Straver ME, et al. Radiotherapy or surgery of the axilla after a positive sentinel node in breast cancer (EORTC 10981-22023 AMAROS): a randomised, multicentre, open-label, phase 3 non-inferiority trial. Lancet Oncol. 2014;15(12):1303-10. doi:10.1016/S1470-2045(14)70460-7.

22. Gatzemeier W, Mann GB. Which sentinel lymph-node (SLN) positive breast cancer patient needs an axillary lymph-node dissection (ALND)-ACOSOG Z0011 results and beyond. Breast. 2013;22(3):211-6. doi:10.1016/j.breast.2013.02.001.

23. Allemani C, Matsuda T. et al. Global surveillance of trends in cancer survival 2000-14 (CONCORD-3): analysis of individual records for $37+\varangle 513+\varangle 025$ patients diagnosed with one of 18 cancers from 322 population-based registries in 71 countries. Lancet. 2018;391(10125):1023-75. 10.1016/S0140-6736(17)33326-3., Di Carlo V. ; ). doi.

24. Simon SD, Bines J, Werutsky G, et al. Characteristics and prognosis of stage I-III breast cancer subtypes in Brazil: The AMAZONA retrospective cohort study. Breast. 2019;44:113-9. doi:10.1016/j.breast.2019.01.008.

25. Van Zee KJ, Manasseh DM, Bevilacqua JL, et al. A nomogram for predicting the likelihood of additional nodal metastases in breast cancer patients with a positive sentinel node biopsy. Ann Surg Oncol. 2003;10(10):1140-51. doi:10.1245/aso.2003.03.015. 
26. Mittendorf EA, Hunt KK, Boughey JC, et al. Incorporation of sentinel lymph node metastasis size into a nomogram predicting nonsentinel lymph node involvement in breast cancer patients with a positive sentinel lymph node. Ann Surg. 2012;255(1):10915. doi:10.1097/SLA.0b013e318238f461.

27. Haffty BG, Hunt KK, Harris JR, Buchholz TA. Positive sentinel nodes without axillary dissection: implications for the radiation oncologist. J Clin Oncol. 2011;29(34):4479-81. doi:10.1200/JC0.2011.36.1667.

28. Bishop JA, Sun J, Ajkay N, Sanders MA. Decline in Frozen Section Diagnosis for Axillary Sentinel Lymph Nodes as a Result of the American College of Surgeons Oncology Group Z0011 Trial. Arch Pathol Lab Med. 2016;140(8):830-5. doi:10.5858/arpa.20150296-OA.

29. Jorns JM, Kidwell KM. Sentinel Lymph Node Frozen-Section Utilization Declines After Publication of American College of Surgeons Oncology Group Z0011 Trial Results With No Change in Subsequent Surgery for Axillary Lymph Node Dissection. Am J Clin Pathol. 2016;146(1):57-66. doi:10.1093/ajcp/aqw078.

30. Fillion MM, Glass KE, Hayek J, et al. Healthcare Costs Reduced After Incorporating the Results of the American College of Surgeons Oncology Group Z0011 Trial into Clinical Practice. Breast J. 2017;23(3):275-81. doi:10.1111/tbj.12728.

31. Camp MS, Greenup RA, Taghian A, et al. Application of ACOSOG Z0011 criteria reduces perioperative costs. Ann Surg Oncol. 2013;20(3):836-41. doi:10.1245/s10434-012-2664-0.

32. Nowikiewicz T, Zegarski W, Pagacz K, et al. The current application of ACOSOG Z0011 trial results: Is further implementation of sentinel lymph node intra-operative histopathological examination mandatory in breast cancer patients - a single-centre analysis. Neoplasma. 2018;65(3):449-54. doi:10.4149/neo_2018_170321N202.

33. van der Noordaa MEM, Vrancken Peeters MTFD, Rutgers EJT. The intraoperative assessment of sentinel nodes - Standards and controversies. Breast. 2017;34(Suppl 1):64-9. doi:10.1016/j.breast.2017.06.031.

34. Chung A, Gangi A, Mirocha J, Giuliano A. Applicability of the ACOSOG Z0011 criteria in women with high-risk node-positive breast cancer undergoing breast conserving surgery. Ann Surg Oncol. 2015;22(4):1128-32. doi:10.1245/s10434-014-4090-y.

35. Kittaka N, Tokui R, Ota C, et al. A prospective feasibility study applying the ACOSOG Z0011 criteria to Japanese patients with early breast cancer undergoing breast-conserving surgery. Int J Clin Oncol. 2018;23(5):860-6. doi:10.1007/s10147-018-1297-0.

36. Morigi C, Peradze N, Galimberti V, et al. Feasibility and surgical impact of Z0011 trial criteria in a single-Institution practice. Breast J. 2020;26(7):1330-6. doi:10.1111/tbj.13851.

37. Jung J, Kim BH, Kim J, et al. Validating the ACOSOG Z0011 Trial Result: A Population-Based Study Using the SEER Database. Cancers (Basel). 2020;12(4):950. doi:10.3390/cancers12040950. Published 2020 Apr 11.

38. Tseng J, Alban RF, Siegel E, Chung A, Giuliano AE, Amersi FF. Changes in utilization of axillary dissection in women with invasive breast cancer and sentinel node metastasis after the ACOSOG Z0011 trial. Breast J. 2021;27(3):216-21. doi:10.1111/tbj.14191.

39. Peristeri DV, Harissis HV. Axillary lymph node dissection vs sentinel biopsy only among women with early-stage breast cancer and sentinel node metastasis: A systematic review and meta-analysis. Breast J. 2021;27(2):158-64. doi:10.1111/tbj.14140.

40. Huang TW, Su CM, Tam KW. Axillary Management in Women with Early Breast Cancer and Limited Sentinel Node Metastasis: A Systematic Review and Metaanalysis of Real-World Evidence in the Post-ACOSOG Z0011 Era [published correction appears in Ann Surg Oncol. 2020 Aug 10;:]. Ann Surg Oncol. 2021;28(2):920-9. doi:10.1245/s10434-020-08923-7.

41. Almahariq MF, Levitin R, Quinn TJ, et al. Omission of Axillary Lymph Node Dissection is Associated with Inferior Survival in Breast Cancer Patients with Residual N1 Nodal Disease Following Neoadjuvant Chemotherapy. Ann Surg Oncol. 2021;28(2):930-40. doi:10.1245/s10434-020-08928-2.

42. Gooch J, King TA, Eaton A, et al. The extent of extracapsular extension may influence the need for axillary lymph node dissection in patients with T1-T2 breast cancer. Ann Surg Oncol. 2014;21(9):2897-903. doi:10.1245/s10434-014-3752-0.

43. Choi AH, Blount S, Perez MN, et al. Size of Extranodal Extension on Sentinel Lymph Node Dissection in the American College of Surgeons Oncology Group Z0011 Trial Era. JAMA Surg. 2015;150(12):1141-8. doi:10.1001/jamasurg.2015.1687.

44. Barrio AV, Downs-Canner S, Edelweiss M, et al. Microscopic Extracapsular Extension in Sentinel Lymph Nodes Does Not Mandate Axillary Dissection in Z0011-Eligible Patients. Ann Surg Oncol. 2020;27(5):1617-24. doi:10.1245/s10434-019-08104-1.

45. Morrow M, Van Zee KJ, Patil S, et al. Axillary Dissection and Nodal Irradiation Can Be Avoided for Most Node-positive Z0011eligible Breast Cancers: A Prospective Validation Study of 793 Patients. Ann Surg. 2017;266(3):457-62. doi:10.1097/SLA.0000000000002354. 
46. Goyal A, Dodwell D. POSNOC: A Randomised Trial Looking at Axillary Treatment in Women with One or Two Sentinel Nodes with Macrometastases. Clin Oncol (R Coll Radiol). 2015;27(12):692-5. doi:10.1016/j.clon.2015.07.005.

47. de Boniface J, Frisell J, Andersson Y, et al. Survival and axillary recurrence following sentinel node-positive breast cancer without completion axillary lymph node dissection: the randomized controlled SENOMAC trial. BMC Cancer. 2017;17(1):379. Published 2017 May 26. doi:10.1186/s12885-017-3361-y.

48. Houvenaeghel G, Cohen M, Raro P, et al. Overview of the pathological results and treatment characteristics in the first 1000 patients randomized in the SERC trial: axillary dissection versus no axillary dissection in patients with involved sentinel node. BMC Cancer. 2018;18(1):1153. Published 2018 Nov 21. doi:10.1186/s12885-018-5053-7.

49. Algara López M, Rodríguez García E, Beato Tortajada I, et al. OPTimizing Irradiation through Molecular Assessment of Lymph node (OPTIMAL): a randomized open label trial. Radiat Oncol. 2020;15(1):229. Published 2020 Oct 2. doi:10.1186/s13014-02001672-7.

\section{Tables}

Table 1. Baseline clinical characteristics and follow-up in patients with breast cancer 


\begin{tabular}{|c|c|c|c|c|c|c|c|c|c|}
\hline & Mean & $\begin{array}{l}\text { Standard } \\
\text { deviation }\end{array}$ & Minimum & Maximum & $\begin{array}{l}\text { First } \\
\text { quartile }\end{array}$ & Median & $\begin{array}{l}\text { Third } \\
\text { quartile }\end{array}$ & $\mathbf{N}$ & $\mathrm{p}^{*}$ \\
\hline Age & 57.8 & 11.5 & 29.0 & 93.0 & 49.0 & 58.0 & 66.0 & 415 & 0.456 \\
\hline SLND alone & 58.3 & 12.3 & 34.0 & 84.0 & 49.3 & 58.0 & 67.8 & 56 & \\
\hline ALND & 56.3 & 12.8 & 33.0 & 77.0 & 46.0 & 58.0 & 66.5 & 41 & \\
\hline Tumor size (cm) & 1.7 & 1.1 & 0.0 & 6.2 & 1.0 & 1.5 & 2.3 & 415 & 0.048 \\
\hline SLND alone & $1.8^{\mathrm{B}^{\prime}}$ & 0.9 & 0.0 & 4.5 & 1.2 & 1.7 & 2.3 & 56 & \\
\hline ALND & $2.2^{\mathrm{A}^{\prime}}$ & 1.1 & 0.1 & 4.5 & 1.4 & 2.0 & 3.1 & 41 & \\
\hline Positive lymph nodes & 0.5 & 1.8 & 0.0 & 24.0 & 0.0 & 0.0 & 0.0 & 415 & 0.002 \\
\hline SLND alone & $1.1^{\mathrm{B}^{\prime}}$ & 0.3 & 1.0 & 2.0 & 1.0 & 1.0 & 1.0 & 56 & \\
\hline ALND & $3.5^{\mathrm{A}^{\prime}}$ & 4.5 & 1.0 & 24.0 & 1.0 & 2.0 & 4.0 & 41 & \\
\hline Resected lymph nodes & 3.9 & 4.5 & 1.0 & 30.0 & 1.0 & 2.0 & 4.0 & 415 & $<0.001$ \\
\hline SLND alone & $2.7^{\mathrm{B}^{\prime}}$ & 2.1 & 1.0 & 12.0 & 1.0 & 2.0 & 4.0 & 56 & \\
\hline ALND & $14.5^{\mathrm{A}^{\prime}}$ & 5.4 & 5.0 & 30.0 & 11.5 & 14.0 & 18.0 & 41 & \\
\hline $\begin{array}{l}\text { Immunohistochemistry } \\
\text { (ki67) }\end{array}$ & $23.3 \%$ & $20.3 \%$ & $1.0 \%$ & $90.0 \%$ & $10.0 \%$ & $20.0 \%$ & $30.0 \%$ & 379 & 0.519 \\
\hline SLND alone & $22.8 \%$ & $20.3 \%$ & $5.0 \%$ & $80.0 \%$ & $10.0 \%$ & $14.5 \%$ & $30.0 \%$ & 54 & \\
\hline ALND & $25.6 \%$ & $17.9 \%$ & $5.0 \%$ & $90.0 \%$ & $10.0 \%$ & $20.0 \%$ & $38.8 \%$ & 32 & \\
\hline Follow-up (years) & 4.3 & 2.5 & 0.1 & 13.8 & 2.3 & 4.2 & 5.8 & 415 & 0.012 \\
\hline SLND alone & $3.7^{\mathrm{B}}$ & 1.9 & 0.8 & 8.1 & 2.0 & 3.5 & 5.0 & 56 & \\
\hline ALND & $5.0^{\mathrm{A}}$ & 2.9 & 0.8 & 10.4 & 2.2 & 5.3 & 7.4 & 41 & \\
\hline
\end{tabular}

*Student's $t$ test for comparison of mean values between two groups.

(A) and (B) are different means according to the multiple comparisons of Duncan.

$\left(A^{\prime}\right)$ and $\left(B^{\prime}\right)$ are different means according to the multiple comparisons of Dunn-Bonferroni.

ALND = complete axillary lymph node dissection; SLND = sentinel lymph node dissection

Table 2. Distribution of demographics and clinical characteristics of patients 


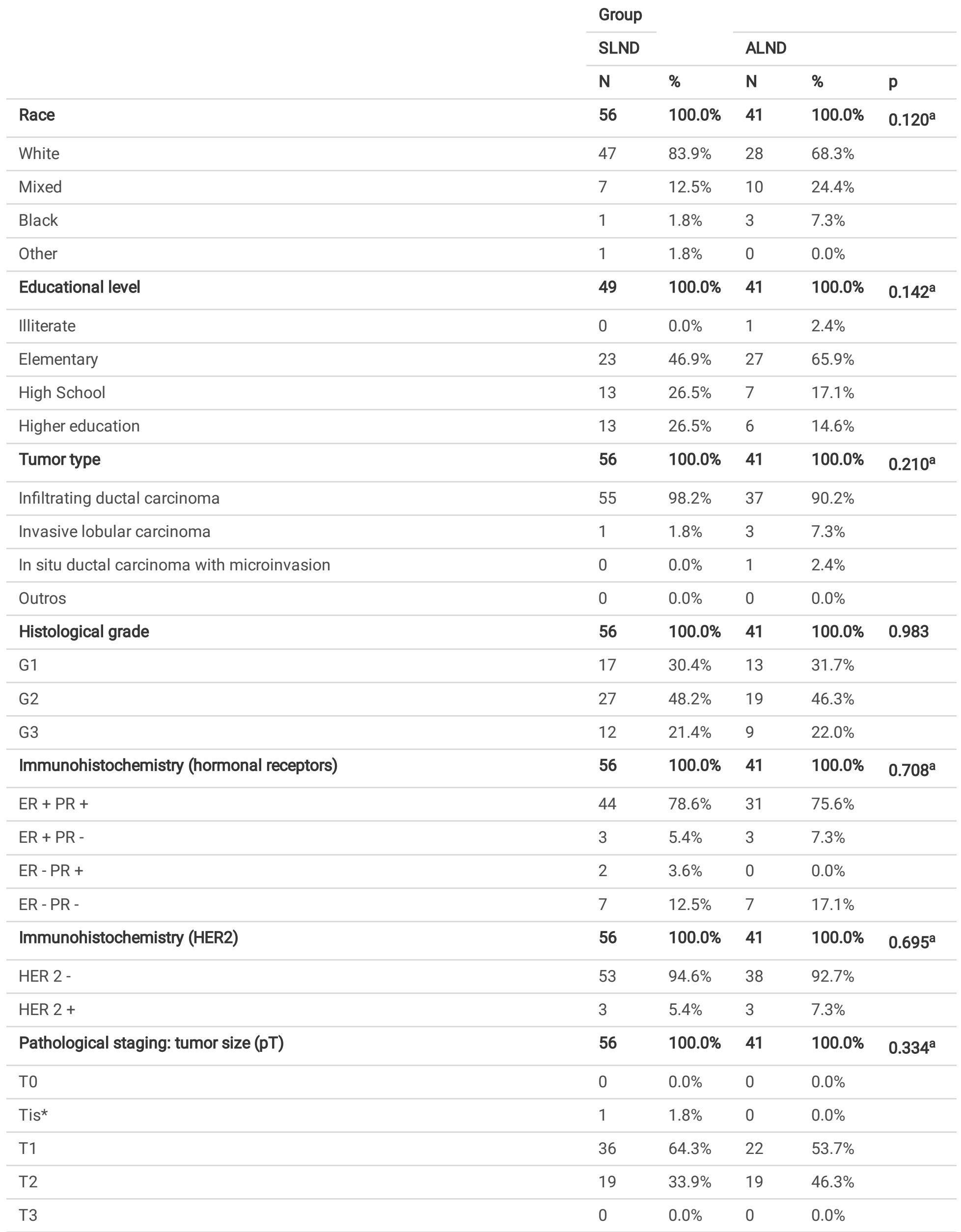

Page 13/23 


\begin{tabular}{lllll}
56 & $100.0 \%$ & 41 & $100.0 \%$ & $<0.001^{\mathrm{a}}$ \\
\hline 0 & $0.0 \%$ & 0 & $0.0 \%$ & \\
\hline
\end{tabular}

\begin{tabular}{|c|c|c|c|c|c|}
\hline No & 0 & $0.0 \%$ & 0 & $0.0 \%$ & \\
\hline NO i+ & 1 & $1.8 \%$ & 0 & $0.0 \%$ & \\
\hline $\mathrm{N} 1 \mathrm{mi}$ & 20 & $35.7 \%$ & 1 & $2.4 \%$ & \\
\hline N1 & 35 & $62.5 \%$ & 30 & $73.2 \%$ & \\
\hline N2 & 0 & $0.0 \%$ & 8 & $19.5 \%$ & \\
\hline N3 & 0 & $0.0 \%$ & 2 & $4.9 \%$ & \\
\hline Angiolymphatic invasion & 56 & $100.0 \%$ & 41 & $100.0 \%$ & 0.641 \\
\hline Yes & 26 & $46.4 \%$ & 21 & $51.2 \%$ & \\
\hline No & 30 & $53.6 \%$ & 20 & $48.8 \%$ & \\
\hline Capsular extension & 56 & $100.0 \%$ & 41 & $100.0 \%$ & $<0.001$ \\
\hline Yes & 5 & $8.9 \%$ & 17 & $41.5 \%$ & \\
\hline No & 51 & $91.1 \%$ & 24 & $58.5 \%$ & \\
\hline Axillary metastasis & 56 & $100.0 \%$ & 41 & $100.0 \%$ & $<0.001^{a}$ \\
\hline Micrometastasis & 20 & $35.7 \%$ & 1 & $2.4 \%$ & \\
\hline Macrometastasis & 35 & $62.5 \%$ & 40 & $97.6 \%$ & \\
\hline Isolated tumoral cell & 1 & $1.8 \%$ & 0 & $0.0 \%$ & \\
\hline Adjuvant chemotherapy & 56 & $100.0 \%$ & 41 & $100.0 \%$ & 0.024 \\
\hline No & 14 & $25.0 \%$ & 3 & $7.3 \%$ & \\
\hline Yes & 42 & $75.0 \%$ & 38 & $92.7 \%$ & \\
\hline Radiotherapy & 56 & $100.0 \%$ & 41 & $100.0 \%$ & $0.080^{a}$ \\
\hline No & 1 & $1.8 \%$ & 5 & $12.2 \%$ & \\
\hline Yes & 55 & $98.2 \%$ & 36 & $87.8 \%$ & \\
\hline Tangential fields & 39 & $70.0 \%$ & 27 & $66.0 \%$ & 0.12 \\
\hline Tangential fields and drains & 7 & $12.5 \%$ & 2 & $4.9 \%$ & \\
\hline Unknown & 9 & $16.0 \%$ & 7 & $17.0 \%$ & \\
\hline Hormonal therapy & 56 & $100.0 \%$ & 41 & $100.0 \%$ & 0.896 \\
\hline No & 9 & $16.1 \%$ & 7 & $17.1 \%$ & \\
\hline Yes & 47 & $83.9 \%$ & 34 & $82.9 \%$ & \\
\hline
\end{tabular}

(a) Chi-squared or Fisher's exact test.

$\mathrm{T} 0=$ no evidence of primary tumor; $\mathrm{Tis}=$ ductal carcinoma in situ; $\mathrm{T} 1=$ tumor size is $2 \mathrm{~cm}$ or less across;

$\mathrm{T} 2=$ tumor size $20-50 \mathrm{~mm}, \mathrm{~T} 3=$ tumor size is more than $5 \mathrm{~cm}$ across .

$\mathrm{NO} \mathrm{i+}=$ the area of cancer spread contains fewer than 200 isolated tumor cells and is smaller

than $0.2 \mathrm{~mm}$ (cancer cells seen in routine stains or immunohistochemistry); $\mathrm{N} 1 \mathrm{mi}=$ micrometastasis to lymph node

N1 = 1-3 lymph nodes affected; N2 = 4-9 lymph nodes affected; N3 = 10 or more lymph nodes affected. 
*This patient had her whole $0.5 \mathrm{~cm}$ invasive tumor removed during percutaneous biopsy.

However, she was later classified clinically as T1a.

$\mathrm{ER}=$ estrogen receptor; HER2 = human epidermal growth factor receptor 2; PR = progesterone receptor

Table 3. Kaplan-Meier survival analysis in patients with breast cancer undergoing ALND or SLND 
Accumulated \% of survival

1 year

100.0

Total

Group

SLND alone

ALND

Age

$\leq 50$ years old

51 years or older

\section{Race}

White

Not white

\section{Educational level}

Illiterate

Elementary

High School

Higher education

\section{Tumor type}

Infiltrating ductal

Invasive lobular carcinoma

In situ ductal carcinoma with

microinvasion

\section{Histological grade}

G1

G2

G3

Immunohistochemistry (hormone receptors)

$\begin{array}{lr}E R+P R+ & 100.0 \\ E R+P R- & 100.0 \\ E R-P R+ & 100.0\end{array}$

ER - PR -

Immunohistochemistry (HER2)

HER 2 -

HER $2+$

\begin{tabular}{|l|}
\hline 100.0 \\
\hline 100.0 \\
\hline 100.0 \\
\hline 100.0 \\
\hline 100.0 \\
\hline 100.0 \\
\hline 100.0 \\
\hline 100.0 \\
\hline 100.0 \\
\hline 100.0 \\
\hline
\end{tabular}

100.0

100.0

$\begin{array}{lll}2 \text { years } & 5 \text { years } & 10 \\ & \text { years }\end{array}$

$95.2 \pm 2.3 \quad 84.9 \pm 5.0 \quad 79.3 \pm 7.2$

0.376

$\begin{array}{lll}95.8 \pm 2.9 & 80.1 \pm 9.3 & - \\ 94.5 \pm 3.8 & 87.5 \pm 6.0 & 87.5 \pm 6.0\end{array}$

0.722

$\begin{array}{lll}89.5 \pm 5.7 & 89.5 \pm 5.7 & - \\ 98.0 \pm 1.9 & 81.8 \pm 7.2 & 71.6 \pm \\ & & 11.5\end{array}$

11.5

0.722

$\begin{array}{ll}90.2 \pm 6.6 & 81.2 \pm \\ & 10.4\end{array}$




$\begin{array}{ccccc}\text { Tis } & 100.0 & 100.0 & - & - \\ \text { T1 } & 100.0 & 92.1 \pm 3.8 & 88.6 \pm 5.0 & 79.7 \pm 9.5 \\ \text { T2 } & 100.0 & 100.0 & 74.5 \pm & -\end{array}$

Pathological staging: nodes (pN)

0.705

$\begin{array}{ll}\mathrm{N} 0 \mathrm{i} & \\ \mathrm{N} 1 \mathrm{mi} & 1 \\ \mathrm{~N} 1 & 1 \\ \mathrm{~N} 2 & 1 \\ \mathrm{~N} 3 & 1\end{array}$

100.0

$100.0 \quad 100.0$

100.0

$94.1 \pm 5.7 \quad 88.2 \pm 7.8 \quad-$

Angiolymphatic invasion

100.0

$96.4 \pm 2.5 \quad 86.6 \pm 6.1 \quad 86.6 \pm 6.1$

100.0

$\begin{array}{ll}87.5 \pm & 70.0 \pm \\ 11.7 & 18.2\end{array}$

$\begin{array}{ll}100.0 & 100.0\end{array}$

$\begin{array}{ll}\text { No } & 100.0 \\ \text { Yes } & 100.0\end{array}$

$\begin{array}{lll}93.0 \pm 3.9 & 88.1 \pm 6.0 & 88.1 \pm 6.0 \\ 97.4 \pm 2.5 & 81.3 \pm 8.2 & -\end{array}$

0.435

Capsular extension

$\begin{array}{llll}100.0 & 95.5 \pm 2.6 & 88.0 \pm 4.9 & 82.1 \pm 7.3 \\ 100.0 & 94.1 \pm 5.7 & 65.9 \pm \\ & 20.0\end{array}$

0.188

$\begin{array}{ll}\text { No } & 100.0 \\ \text { Yes } & 100.0\end{array}$

Axillary metastasis

Micrometastasis

100.0

Macrometastasis

100.0

Isolated tumoral cell

100.0

$94.1 \pm 5.7$

$88.2 \pm 7.8$

$95.4 \pm 2.6 \quad 84.1 \pm 6.0$

$84.1 \pm 6.0$

100.0

100.0

Adjuvant chemotherapy

No

100.0

$92.9 \pm 6.9 \quad 57.1 \pm$

17.6

0.059

Yes

100.0

$95.7 \pm 2.4 \quad 91.1 \pm 4.1$

$57.1 \pm$

17.6

\section{Radiotherapy}

No

100.0

100.0

$66.7 \pm$

19.2

Yes

100.0

$94.8 \pm 2.5$

$86.5 \pm 5.2 \quad 80.3 \pm 7.6$

\section{Hormonal therapy}

No

100.0

100.0

Yes

Tis = ductal carcinoma in situ; $\mathrm{T} 2=$ tumor size $20-50 \mathrm{~mm}$. NOi+ = the area of cancer spread contains fewer than 200 isolated tumor cells and is smaller than $0.2 \mathrm{~mm}$ (cancer cells seen in routine stains or immunohistochemistry);

$\mathrm{N} 1 \mathrm{mi}=$ micrometastasis to lymph node; N1 = 1-3 lymph nodes affected; N2 = 4-9 lymph nodes affected;

$\mathrm{N} 3=10$ or more lymph nodes affected; ER = estrogen receptor; $\mathrm{PR}=$ progesterone receptor.

HER2 = human epidermal growth factor receptor 2; SLND = sentinel lymph node dissection; 
ALND = complete axillary lymph node dissection.

Table 4. Survival analysis using Cox univariate regression in patients with breast cancer undergoing ALND or SLND 
SLND (reference: ALND)

$1.80(0.48-6.77) \quad 0.386$

Race not white (reference: white)

$1.27(0.33-4.94) \quad 0.725$

Age (years)

$0.97(0.92-1.03) \quad 0.307$

Age $\leq 50$ years (reference: 51 years and older)

$0.78(0.20-3.05) \quad 0.726$

Educational level (reference: Elementary)

Illiterate

$0.00(-)$

0.990

High School

$1.25(0.25-6.29)$

0.790

Higher education

$1.57(0.31-7.83)$

0.584

Diagnosis (reference: infiltrating ductal carcinoma)

0.201

Invasive lobular carcinoma

0.073

In situ ductal carcinoma with microinvasion

$\begin{array}{ll}7.12(0.83-61.07) & 0.073 \\ 0.00(-) & 0.987\end{array}$

Histological grade (reference: G2)

0.591

G1

$0.67(0.13-3.47)$

0.632

G3

$1.68(0.39-7.14)$

0.485

Immunohistochemistry - hormone receptors (reference: ER + PR +)

0.062

$E R+P R-$

$0.00(-)$

0.989

$\mathrm{ER}-\mathrm{PR}+$

$16.75(1.86-150.91)$

0.012

ER - PR -

$2.87(0.71-11.51)$

0.137

Immunohistochemistry - HER2 (reference: HER 2 -)

$0.05(-)$

0.601

Pathological staging: tumor size (pT) (reference: T1)

0.949

Tis

$0.00(-)$

0.990

T2

$1.23(0.35-4.41)$

0.746

Pathological staging: nodes (reference: N1)

NO i+

$0.00(-)$

0.991

$\mathrm{N} 1 \mathrm{mi}$

N2

$1.99(0.47-8.35)$

0.346

N3

$2.58(0.50-13.40)$

0.259

$0.00(-)$

0.991

Angiolymphatic invasion (reference: no)

$1.64(0.46-5.81)$

0.444

Capsular extension (reference: no)

$2.47(0.61-10.02)$

0.206

Axillary metastasis (reference: macrometastasis)

Micrometastasis

$1.68(0.43-6.52)$

0.452

Isolated tumoral cell

$0.00(-)$

0.991

Adjuvant chemotherapy (reference: no)

$0.32(0.09-1.13)$

0.077

Radiotherapy (reference: no)

$0.29(0.06-1.39)$

0.122

Hormonal therapy (reference: no)

$0.22(0.06-0.77)$

0.018

Immunohistochemistry (ki67)

$0.99(0.95-1.04)$

0.773

Page 19/23 
$(-)$ not shown due to lack of precision. $\mathrm{HR}=$ hazard ratio. $\mathrm{T}$ is $=$ ductal carcinoma in situ; $\mathrm{T} 1=$ tumor size $\mathrm{T} 2=$ tumor size 20-50 $\mathrm{mm}$. NOi+ = the area of cancer spread contains fewer than 200 isolated tumor cells and is smaller than $0.2 \mathrm{~mm}$ (cancer cells seen in routine stains or immunohistochemistry); $\mathrm{N} 1 \mathrm{mi}=$ micrometastasis to lymph node; $\mathrm{N} 1=1-3$ lymph nodes affected; N2 = 4-9 lymph nodes affected; N3 = 10 or more lymph nodes affected. ER = estrogen receptor; PR = progesterone receptor;

HER2 = human epidermal growth factor receptor 2; SLND = sentinel lymph node dissection; ALND = complete axillary lymph node dissection

Table 5. Final survival analysis using Cox multivariate regression in patients with breast cancer

\begin{tabular}{lllll} 
Variables & Initial model & & Final model \\
\cline { 2 - 4 } & Adjusted HR (95\%Cl) & $\mathbf{p}$ & Adjusted HR (95\%Cl) & P \\
\hline SLND (reference: ALND) & $1.24(0.05-29.49)$ & 0.895 & $1.55(0.39-6.22)$ & 0.536 \\
\hline Hormonal therapy (reference: no) & $0.05(0.01-0.32)$ & 0.001 & $0.09(0.02-0.48)$ & 0.005 \\
\hline Tumor size (cm) & $1.18(0.57-2.46)$ & 0.656 & - & - \\
\hline Positive lymph nodes & $0.95(0.72-1.24)$ & 0.685 & - & - \\
\hline Resected lymph nodes & $0.99(0.79-1.24)$ & 0.918 & - \\
\hline Capsular extension (reference: no) & $6.52(0.97-43.73)$ & 0.053 & - & - \\
\hline Axillary metastasis (reference: macrometastasis) & & 0,575 & - \\
\hline Micrometastasis & $2.75(0.42-18.05)$ & 0,293 & - & - \\
\hline Isolated tumoral cell & $0.00(-)$ & 0,99 & - & - \\
\hline Adjuvant chemotherapy (reference: no) & $0.17(0.03-1.13)$ & 0,066 & $0.14(0.02-0.8)$ & 0.027
\end{tabular}

$\mathrm{Cl}=$ confidence interval; $\mathrm{HR}=$ hazard ratio; $\mathrm{SLND}$ = sentinel lymph node dissection; $\mathrm{ALND}=$ complete axillary lymph node dissection

\section{Figures}




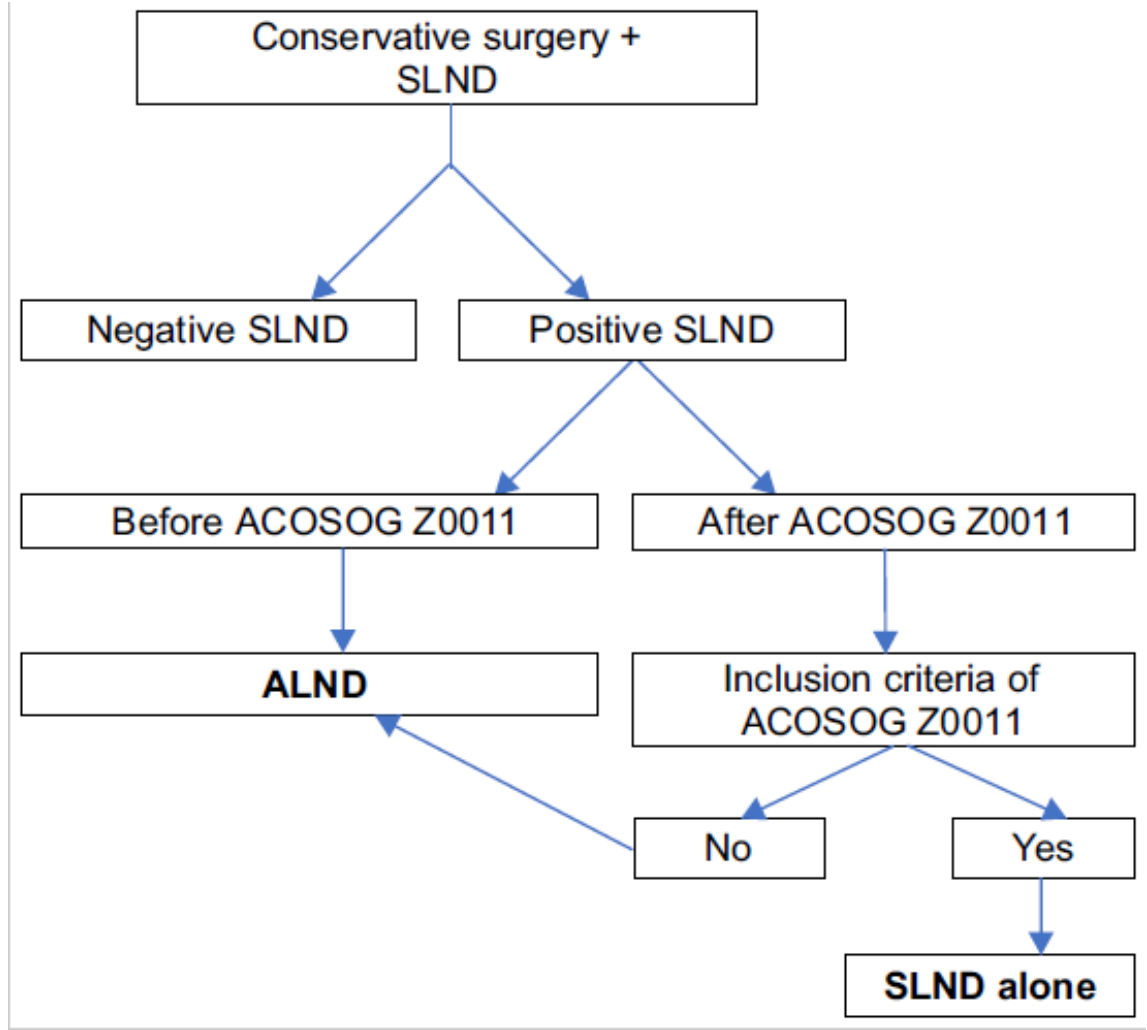

\section{Figure 1}

Clinical approach for the treatment of the axilla after the publication of the Z0011 trial Legends: SLND = sentinel lymph node dissection; ALND = complete axillary lymph node dissection

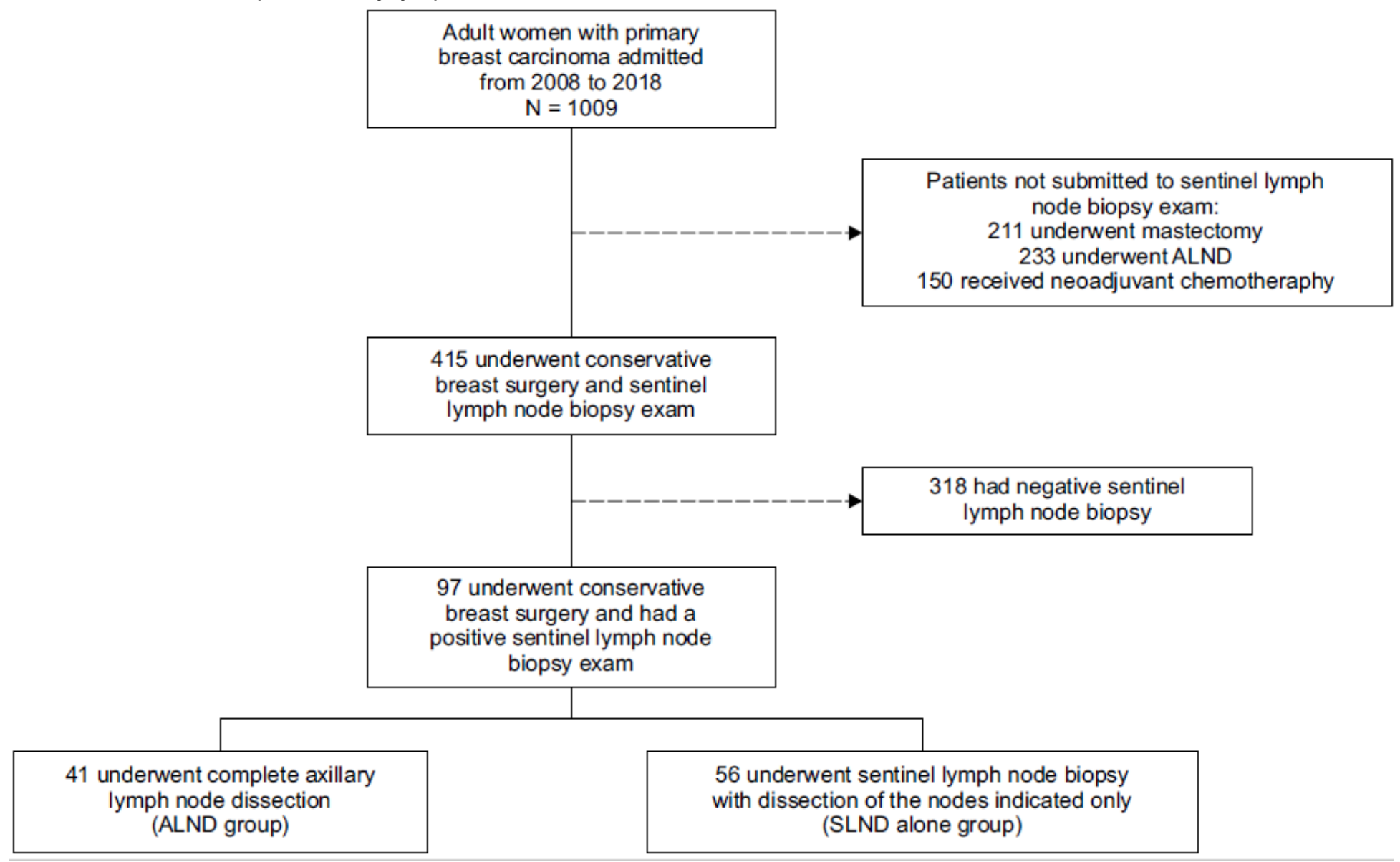




\section{Figure 2}

Flow diagram of patient inclusion procedure used in the study

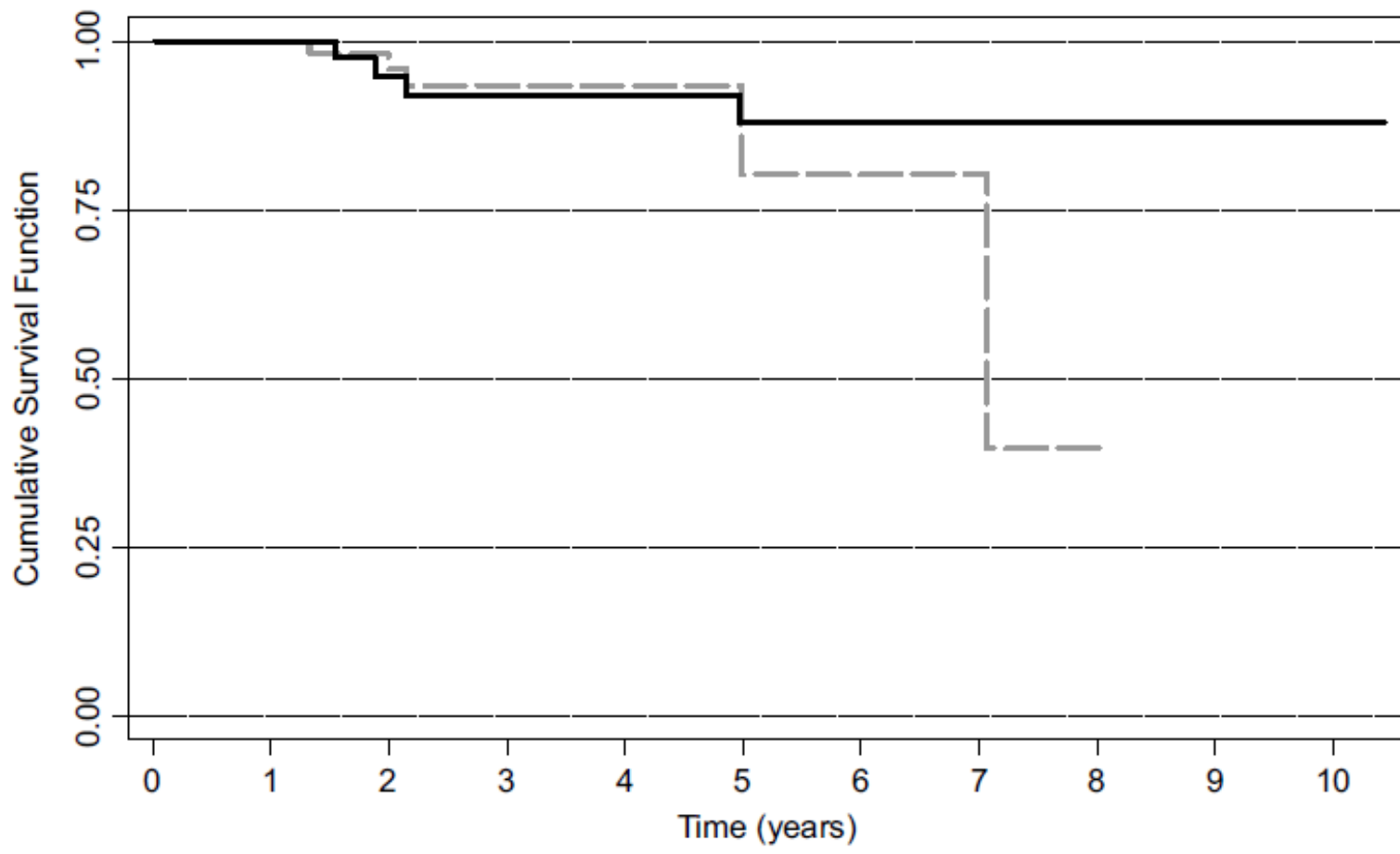

$$
\begin{aligned}
& -\longrightarrow \text { SNLD alone } \longrightarrow \text { ALND } \\
& p=0.376
\end{aligned}
$$

\section{Number at risk}

$\begin{array}{llllllllllll}\text { SNLD alone } & 56 & 55 & 43 & 34 & 25 & 14 & 9 & 4 & 2 & 1 & 1 \\ \text { ALND } & 41 & 40 & 35 & 27 & 23 & 22 & 17 & 14 & 8 & 6 & 3\end{array}$

\section{Figure 3}

Overall survival over time in patients with breast cancer undergoing ALND or SLND alone Legends: SLND = sentinel lymph node dissection; ALND = complete axillary lymph node dissection 


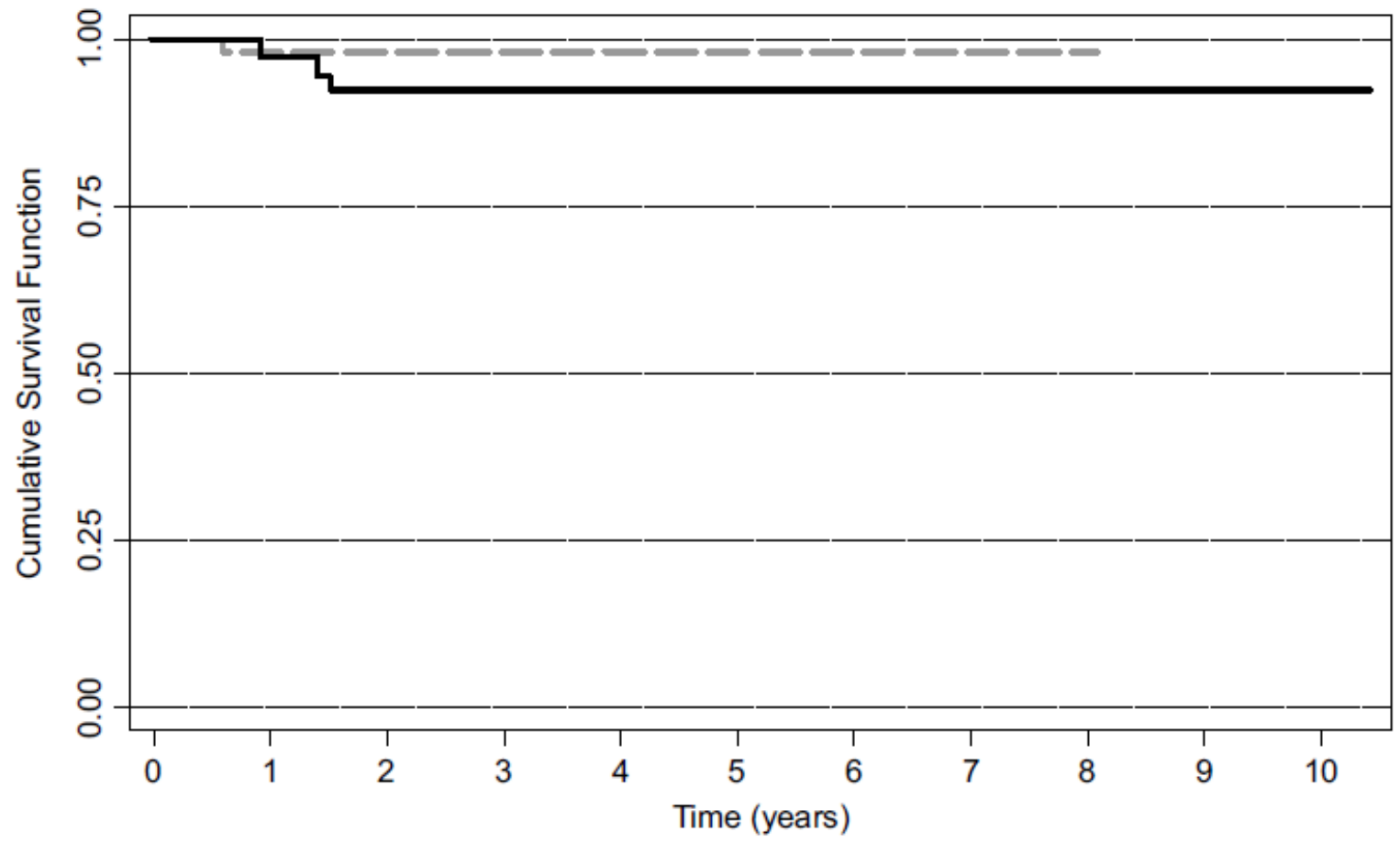

$$
\begin{aligned}
& -\longrightarrow \text { SNLD alone } \longrightarrow \text { ALND } \\
& p=0,196
\end{aligned}
$$

Number at risk

$\begin{array}{llllllllllll}\text { SNLD alone } & 56 & 54 & 43 & 33 & 23 & 12 & 8 & 3 & 3 & 1 & 1 \\ \text { ALND } & 41 & 39 & 33 & 27 & 23 & 22 & 17 & 14 & 8 & 6 & 3\end{array}$

Figure 4

Survival over time in patients with breast cancer and locoregional recurrence Legends: SLND = sentinel lymph node dissection; ALND = complete axillary lymph node dissection 